\title{
BIOPIRATARIA E EXPLORAÇÕES OCORRIDAS NO BRASIL: UM RELATO- DENÚNCIA DE PRÁTICAS CRIMINOSAS CONTRA POVOS INDÍGENAS
}

\author{
BIOPIRACY AND EXPLORATIONS OCCURRED IN BRAZIL: A REPORT- \\ REPORT OF CRIMINAL PRACTICES AGAINST INDIGENOUS PEOPLES
}

\section{BIOPIRACIA Y EXPLORACIONES OCURRIDAS EN BRASIL: INFORME- INFORME DE PRÁCTICAS PENALES CONTRA LOS PUEBLOS INDÍGENAS}

\author{
Matheus Moreira da Silva ${ }^{1}$ (iD) \\ José Pedro Machado Ribeiro ${ }^{2}$ (iD) 9 \\ Rogério Ferreira $^{3}$ (D) 9
}

\begin{abstract}
RESUMO
Este artigo tem como objetivo denunciar o processo de subalternação e (re)colonização comercial em cenários indígenas no Brasil, instaurado com a prática da biopirataria, que transforma a biodiversidade em produtos patenteados por instituições financeiras sem a repartição justa das vantagens por elas obtidas. Trazemos, por meio de relatos-denúncias e de revisão da literatura, as influências de práticas colonialistas que agridem os conhecimentos indígenas, suas práticas comerciais tradicionais, as fronteiras culturais, a biodiversidade e a biotecnologia, sendo ocasionadas por segmentos da sociedade nacional que detêm poder econômico, de modo articulado com as explorações ocorridas na Amazônia e em outros cenários brasileiros. Apresentamos ainda alguns impactos da Constituição de 1988, no que tange à prática da biopirataria, que evidenciam o desrespeito a normativas de Direitos Humanos por violentarem saberes e viveres dos povos indígenas.
\end{abstract}

Palavras-chave: Povos indígenas. Biodiversidade. Biopirataria. Comércio indígena.

\begin{abstract}
This article aims to denounce the process of subordination and commercial (re) colonization in indigenous scenarios in Brazil, established with the practice of biopiracy, which transforms biodiversity into products patented by financial institutions without the fair sharing of the advantages obtained by them . We bring, through reports-denunciations and literature review, the influences of colonialist practices that attack indigenous knowledge, their traditional commercial practices, cultural frontiers, biodiversity and biotechnology, being caused by segments of national society that hold power economic, in an articulated way with the explorations that took place in the Amazon and in other Brazilian scenarios. We also present some impacts of the 1988 Constitution, with respect to the practice of

\footnotetext{
${ }^{1}$ Mestre em Educação em Ciências e Matemática - UFG. Aluno de doutorado no Programa de Pós-Graduação em Educação em Ciências e Matemática pela UFG, Goiânia, Goiás, Brasil. Membro do Matema - Grupo de Pesquisa e Formação em Educação Matemática. Endereço para correspondência: Av. Fuad Rassi, Condômino Parque Oeste, Apt. 404 - Torre 10, Bairro Goiá, Goiânia, Goiás, Brasil, CEP: 74485-035. E-mail: matt.moreira.pet@gmail.com. ${ }^{2}$ Doutor em Educação - USP. Professor Associado da Universidade Federal de Goiás. Líder do Matema - Grupo de Pesquisa e Formação em Educação Matemática. Endereço para correspondência: Instituto de Matemática e Estatística, Universidade Federal de Goiás - Campus Samambaia - R. Jacarandá - Chácaras Califórnia, Goiânia GO, CEP: 74001-970. E-mail: zepedro@ufg.br.

${ }^{3}$ Doutor em Educação - USP. Professor Associado da Universidade de Brasília (UnB), Brasília, DF, Brasil. Endereço para correspondência: Campus UnB Darcy Ribeiro, Colina, Bloco I, Ap. 204, Asa Norte, Brasília, DF, Brasil, CEP: 70904-109. E-mail: rogeriof@unb.br.
} 
biopiracy, which show the disrespect to Human Rights norms for violating the knowledge and life of indigenous peoples.

Keywords: Indigenous peoples. Biodiversity. Biopiracy. Indigenous trade.

\section{RESUMEN}

Este artículo tiene como objetivo denunciar el proceso de subordinación y (re) colonización comercial en escenarios indígenas en Brasil, establecido con la práctica de la biopiratería, que transforma la biodiversidad en productos patentados por instituciones financieras sin el reparto equitativo de las ventajas obtenidas por ellas. Traemos, a través de informes-denuncias y revisión de literatura, las influencias de prácticas colonialistas que atacan el conocimiento indígena, sus prácticas comerciales tradicionales, fronteras culturales, biodiversidad y biotecnología, siendo provocadas por segmentos de la sociedad nacional que ostentan el poder económico, de manera articulada con las exploraciones que tuvieron lugar en la Amazonía y en otros escenarios brasileños. También presentamos algunos impactos de la Constitución de 1988, con respecto a la práctica de la biopiratería, que muestran la falta de respeto a las normas de Derechos Humanos por violar el conocimiento y la vida de los pueblos indígenas.

Palabras clave: pueblos indígenas. Biodiversidad. Biopiratería. Comercio indígena.

\section{DEBATE INICIAL: INFLUENCIAS DO CAPITALISMO SOBRE AS RELAÇÕES COMERCIAIS INDÍGENAS}

Historicamente, o pensamento colonialista corrobora a visão agressiva de os povos indígenas ${ }^{4}$ serem grupos isolados, com culturas ${ }^{5}$ periféricas e marginais. Para Taukane (2003), esses povos são comumente caracterizados, por não indígenas, como desfavorecidos, sendo marcados por discriminação, exclusão social e exploração.

No Brasil, existem diversos povos com representações culturais distintas, línguas e saberes próprios - a diversidade sociocultural é característica marcante da realidade brasileira. Em relação aos povos indígenas, o censo de 2010, do Instituto Brasileiro de Geografia e Estatística (IBGE), esclarece que "[...] o Brasil é composto por 305 etnias indígenas e 274 línguas distintas" (p. 5), com diferentes formas de perceber e lidar com o mundo, já que um mundo sem diversidade é um mundo morto. Nesse viés, as concepções que Taukane (2003, p. 11) discute estão amparadas por uma trama complexa de saberes,

\footnotetext{
${ }^{4}$ Há uma diversidade de povos indígenas no Brasil, nem todos vivem na Amazônia e cada povo tem sua cultura e seu modo próprio de lidar, enfrentar, utilizar ou mesmo sofrer os efeitos da biopirataria. Dessa forma, trazemos neste artigo um relato-denúncia - por meio de revisão da literatura - problemas e enfretamentos presentes na Amazônia e que também acontecem com outros povos de diversas regiões.

${ }_{5}^{5}$ Para Laraia (2002), o termo "cultura" é um dos temas centrais mais discutidos nos últimos 100 anos pelos antropólogos; o assunto tem se demonstrado inesgotável. O desenvolvimento desse termo é útil para a compreensão do paradoxo da vasta diversidade cultural da humanidade. É complexo: inclui conhecimentos, crenças, arte, moral, leis, costumes ou qualquer outra capacidade ou hábitos adquiridos pelo homem como membro de uma sociedade. 
Infelizmente existem muitos preconceitos a respeito de nosso povo, talvez pela falta de informação sobre o assunto. Às vezes, o índio, era visto como um selvagem, atrasado e incapaz de lutar por seus direitos, ou como um coitadinho, uma vítima de armação que saía sempre perdendo.

Deparamo-nos com povos que oprimem os indígenas desde 1500, com o advento da chegada dos portugueses ao Brasil. Desde então são utilizadas ideologias que buscam suprimir a diversidade sociocultural, estabelecendo cultura única, na qual todos devem possuir os mesmos valores, hábitos, costumes e tradições. Processos de unificação recorrentemente tipificam práticas colonialistas.

Ao longo do curso histórico dos encontros entre portugueses e povos indígenas, os contatos interculturais estiveram marcados por pressões e pela presença de instituições capitalistas, nas quais prevaleciam olhares impostos pelo invasor/dominador. Por meio de mecanismos de força, substituíram-se elementos culturais e imateriais de povos distintos com a intenção de assumir o espaço indígena, seja ele político, social, econômico ou cultural.

Diante do exposto, surge como propósito para este artigo denunciar o processo de subalternação e (re)colonização comercial em cenários indígenas na Amazônia, instaurado com a prática da biopirataria, que transforma a biodiversidade em produtos patenteados por instituições financeiras sem a repartição justa das vantagens por elas obtidas, que deveriam ser auferidas por meio desses produtos.

Iniciamos este $\operatorname{artigo~}^{6}$ com reflexões sobre a influência do capitalismo nas relações comerciais indígenas, bem como sobre a Constituição Federal de 1988, a evolução do sistema capitalista e a prática da biopirataria. Mostraremos ainda princípios constitucionais frente à defesa do consumidor.

Trazemos, por meio de relatos-denúncias e de revisão da literatura, influências de processos colonialistas que agridem os conhecimentos indígenas, suas práticas comerciais tradicionais, as fronteiras culturais, a biodiversidade e a biotecnologia, ocasionadas por segmentos da sociedade nacional que detêm poder econômico, de modo articulado com as explorações ocorridas na Amazônia e em outros cenários brasileiros. Dessa forma, lançamos mão de olhares pela abordagem hermenêutica, utilizando como opção política e metodológica

\begin{tabular}{l}
${ }^{6}$ Essa discussão faz parte da dissertação de mestrado intitulada: “Etnomatemática e relações comerciais na \\
formação de professores indígenas", defendida junto ao Programa de Pós-Graduação em Educação em Ciências e \\
Matemática, da Universidade Federal de Goiás. defendida junto ao Programa de Pós-Graduação em Educação em \\
Ciências e Matemática, da Universidade Federal de Goiás. \\
\hline
\end{tabular} 
a pedagogia decolonial ${ }^{7}$. Além disso, trazemos alguns impactos da Constituição de 1988 no que tange à existência dos mundos - indígenas e não indígenas -, polarizados e distintos, contradizendo normativas de Direitos $\operatorname{Humanos}^{8}$ por não considerarem a contento os saberes e viveres dos povos indígenas.

A caracterização inicial aqui estabelecida constitui elemento indispensável para aferir necessária consistência acerca dos fenômenos de transição e mudança que sofreram (e sofrem) os povos indígenas em contexto de relações interculturais ${ }^{9}$ e comerciais, e concepções contrárias e abandonadas do termo aculturação.

A análise aqui presente serve de fundamento para a compreensão das relações comerciais indígenas com base na Constituição, para que, dessa forma, possamos fazer uma correlação dos conhecimentos econômicos tradicionais como contrapartida pelos povos indígenas. Ao pretender projetar respostas, eclode a necessidade de rompimento com os limites historicamente estabelecidos que procuram minimizar os efeitos de práticas usurpadoras que violentam saberes, sujeitos, sociedades e culturas indígenas.

Esta seção tem por finalidade, portanto, debater sobre as mudanças do patrimônio cultural $^{10}$ - nas formas de viver e praticar a cultura - e das relações comerciais por meio da prática da biopirataria que, para Barbieri (2014, p. 14), constitui-se “[...] pelo fornecimento de produtos utilizando o conhecimento tradicional como, por exemplo, os produtos farmacêuticos, cosméticos e químicos advindos dos saberes tradicionais ancestrais"; e, em seguida, exibir os prejuízos derivados dessa prática para o patrimônio cultural dos povos indígenas e sua economia. Para Castilho (2009, p. 15),

No contexto do capitalismo, a política ambiental não rara é perversa com aqueles que conservaram, por meio de uso tradicional da terra e dos recursos naturais, as áreas naturais ainda existentes. Ao mesmo tempo que lhes nega o direito de manter seu modo de vida, enxerga-os através de uma lente utilitarista e etnocêntrica, que parece só admitir o direito a existência dos outros se estes servirem a algo para nós.

A citação acima apresenta, diante dos debates do Direito do Consumidor (DC), a lógica capitalista que se configura por meio da biopirataria e da sociedade do consumo. O DC está

\footnotetext{
${ }^{7}$ Para enfrentar esse problema, é importante remeter aos estudos sobre a interculturalidade crítica e a pedagogia decolonial, pois entender os processos econômicos e culturais implica compreender, em parte, a evolução e a inferência dos distintos grupos sociais nas comunidades indígenas.

${ }^{8}$ Direitos estes que quando são vivenciados e afirmados, no Brasil, são percebidos e praticados de formas divergentes entre os não indígenas e indígenas.

${ }^{9}$ Devido ao processo de aculturação, suas relações culturais sofrem processos de transições e modificações.

${ }^{10}$ Entendemos patrimônio cultural como o conjunto complexo de bens imateriais e materiais que formam a identidade de um povo. que formam a identidade de um povo.
} 
presente quando percebemos o processo de comercialização de produtos oriundos dos conhecimentos tradicionais indígenas, em que concebemos clara distinção entre o pensamento do consumidor, que fomenta a referida lógica capitalista, e o pensamento do fornecedor indígena, que cotidianamente constrói e reconstrói seu conhecimento tradicional ${ }^{11}$.

Os prejuízos da biopirataria são nefastos para a economia da população indígena, promovendo a exploração da biodiversidade e dos recursos naturais em suas terras. As relações comerciais indígenas são fortemente caracterizadas pela prática tradicional do escambo. Nessa prática, encontra-se muito da natureza comunitária, compartilhada e solidária dos povos indígenas (sistema de interdependência), a qual vem sendo paulatinamente vilipendiada por mecanismos que ao longo do tempo vêm alicerçando a prática capitalista.

A sociedade que tem em sua base o pensamento colonialista constitui o lucro como foco e, para obtê-lo, utiliza os recursos naturais da população invadida. A exploração dos povos indígenas e de seus territórios está na essência dos movimentos de povos europeus que desencadeiam um processo evolutivo insustentável do chamado mercantilismo. A pesquisadora Rosana Bond (2010, p. 17-18) disserta a esse respeito:

\begin{abstract}
A invasão das Américas, nos séculos 15 e 16, envolveu grupos poderosos de vários pontos da Europa. As navegações, na verdade, não foram bancadas apenas pelos reis espanhóis e portugueses e sim também pelas classes ricas de comerciantes, empresários e financistas europeus, com total respaldo da Igreja. O saque do território americano, por tais grupos de poder, é que ajudou a gerar o capitalismo. A América e suas nações indígenas foram invadidas, conquistadas e colonizadas dentro do processo de expansão do capitalismo comercial, o chamado mercantilismo. O roubo das riquezas do Novo Mundo (incluindo a escravização da mão de obra índia) foi o fator mais importante para a acumulação de capitais pela Europa, possibilitando o primeiro passo para o surgimento de uma nova etapa na economia mundial, a chamada revolução industrial. Isto é, o capitalismo moderno, em sua etapa atual de imperialismo, em fase de decomposição, é "herdeiro" daquele que invadiu a América e massacrou seus povos originários. Este sistema, que desde sempre aplica o lema de Robin Wood ao contrário (tira dos pobres e dá aos ricos), que é o maior responsável pela fome e doenças de milhões de pessoas, além da tão falada crise ambiental de hoje, ligada à poluição das águas e aquecimento do clima, é 'filho' e herdeiro daquele outro. Daquele sistema que, a partir do século 15 , provocou o desastre da civilização indígena americana.
\end{abstract}

A argumentação da autora contribui para entendermos o porquê de os povos indígenas serem permanentemente subalternizados e excluídos em contexto de perversa influência do

\footnotetext{
${ }^{11}$ Para Barbieri (2014), esse conhecimento tradicional é fruto de uma cultura rica, construída de forma ágrafa pelos povos indígenas. 
capitalismo $^{12}$. O desrespeito sociocultural aos povos descoincidentes há tempos se faz ação comum na realidade brasileira.

O embate acerca da sustentabilidade passa necessariamente pela problematização dos mecanismos capitalistas que exploram o meio ambiente, degradando a biodiversidade e violentando a prática tradicional dos povos indígenas. São inúmeros e evidentes os ataques, saques e explorações em seus territórios desde o início do período de colonização do Brasil, em 1500 .

As próximas seções abordarão, respectivamente, o conhecimento indígena como "produto comercial"; as vantagens econômicas em relação às práticas tradicionais dos povos indígenas; a prática da biopirataria na Amazônia como ação nefasta para as relações comerciais indígenas; e a falta de regulação econômica em terras indígenas.

\section{O CONHECIMENTO INDÍGENA COMO "PRODUTO COMERCIAL": LUTAS E DIREITOS EM CONTEXTO DE EXPLORAÇÃO DA BIODIVERSIDADE}

A corrida desenfreada em busca de lucro faz com que o colonizador visualize no conhecimento indígena um produto passível de mercantilização, gerando apropriação criminosa de saberes ancestrais. Essa prática é predatória, visto que não se pode "[...] apropriar-se dos bens culturais, registrá-los após adaptação e devolvê-los como mercadorias protegidas por patentes, inclusive aos países onde tais conhecimentos foram desenvolvidos" (BARBIERI, 2014, p. 58).

A sabedoria indígena, à medida em que é enxergada pelo invasor, chama a atenção pelo valor inestimável dos produtos/conhecimentos que gera. Essa atenção está estreitamente vinculada a uma situação de exploração comercial. Logo, a preservação e a valorização do saber indígena, do qual participa suas relações comerciais tradicionais, veem-se permanentemente ameaçadas.

Os conhecimentos tradicionais indígenas, geradores de práticas comerciais solidárias, são acumulativos e estão em estreita relação com a natureza e o universo. Diferentemente do

\footnotetext{
12 "Uma vez que o Estado continua a insistir no seu caráter onipotente, apesar do discurso pluralista e democrático. Infelizmente, não houve participação intencional dos povos indígenas na formação do Estado brasileiro [...]" (BARBIERI, 2014, p. 18). A participação não foi intencional, contudo, houve muita influência na formação do Estado. Nos 500 anos de formação do Brasil, sempre se teve que levar em consideração políticas que envolviam os indígenas.
} 
conhecimento do sujeito que visa colonizar $^{13}$, a sabedoria ou o conhecimento tradicional indígena promove a diversidade, reduz a incidência de doenças, estabiliza a produção de bens materiais, além de maximizar o retorno das condições simples e adaptadas.

Esses conhecimentos estão protegidos por meio dos artigos 3, 23 e 24 da "Declaração Universal dos Direitos Humanos" e da "Declaração Universal dos Povos Indígenas", divulgada pela ONU, em 2007, que assim fundamentam:

\begin{abstract}
Artigo III - Os indígenas têm o direito à autodeterminação [...] e a buscar livremente seu desenvolvimento econômico, social e cultural.

Artigo XXIII - [...] Em especial, os povos indígenas têm o direito de participar da elaboração dos programas de saúde e demais programas econômicos e sociais. artigo xxiv - os povos indígenas têm o direito de manter, controlar, proteger e desenvolver seu patrimônio cultural, seus conhecimentos tradicionais (ORGANIZAÇÃO DAS NAÇÕES UNIDAS, 2008, p. 23).
\end{abstract}

Em conjunto, os estados brasileiros deveriam adotar, de acordo com a Constituição Federal de 1988, medidas que fossem capazes de proteger e preservar o patrimônio imaterial e comercial dos povos indígenas, por meio da reparação equitativa de atividades econômicas. $\mathrm{O}$ fato é que essas ações de proteção e preservação não se efetivam a contento. Com isso, os povos indígenas têm ficado à mercê de exploradores sem a devida possibilidade de problematizar a situação intercultural na qual são forçosamente posicionados. Nesse contexto, uma questão que recorrentemente surge é se a apropriação da biodiversidade e de técnicas desenvolvidas por povos indígenas pode se tornar legalmente instituída por meio de compensações financeiras? A complexidade do tema aumenta, como mostra Marés (2010, p. 62), quando,

\footnotetext{
As comunidades indígenas entendem que, vetando-se a possibilidade de apropriação por quem quer que seja, estar-se-ia limitando o interesse sobre o conhecimento e a biodiversidade dessas comunidades, na medida em que limitar-se-ia a possibilidade de um eventual titular explorar, em caráter de exclusividade, esse patrimônio.
}

Essa preocupação revela que o contexto secular de exploração colonizadora pode produzir uma perigosa tentativa de associar a lógica do capital a meios formais/legais de apropriação de saberes, gerando novos modos de colonização vinculados ao universo das patentes. Em meio a essa problemática, entendemos que povos indígenas e meio ambiente permanecem na mira do desenvolvimento econômico. Colonização e globalização, juntas, potencializam os processos de degradação, vitimando diferentes sociedades e culturas por todo o mundo e, potencialmente, na realidade brasileira.

13 Conhecimento que aborda o caráter quantitativo, seletivo, exploratório, hierarquizado, verticalizado e reducionista. 
Desde o século XX, as políticas indigenistas transitaram na negação do ser indígena, havendo a incorporação de uma "nova" política econômica para esses povos. O Estado, portanto, desde o último século (re)ordena as políticas públicas destinadas aos povos indígenas em face do mercado e do capitalismo. Essas (re)ordenação e articulação têm gerado epistemicídio e colocado em risco permanente as populações indígenas. Com a ineficácia do estado no controle da biopirataria, conflitos de interesse surgem entre os próprios indígenas, visto que, enquanto alguns visualizam criticamente o perigo que significa a apropriação indevida de seus conhecimentos, outros veem nesse mercado marginal uma oportunidade de buscar dinheiro. Como fica claro, o individualismo que caracteriza o modo de organização capitalista violenta a essência do pensamento comunitário que caracteriza os modos de ser indígenas.

Rodolfo Stavenhagem (1984, p. 34) afirma que esse difícil cenário necessita de uma fundamentação no etnodesenvolvimento ${ }^{14}$, ligado à autonomia e à negociação dos povos indígenas. Para o antropólogo, "esse conceito bem compreendido e interligado com as questões indígenas, proporciona uma maior autonomia aos sujeitos [...]", capaz de entender a dificuldade da comercialização pelo capitalismo. Essa autonomia está vinculada à organização dos povos indígenas mediante a cultura.

Por séculos, os povos indígenas vêm tendo sua autonomia negligenciada, fazendo com que sofram com o impacto do colonialismo político. Quijano (2000) explica o processo de subalternação e dominação como ação da colonialidade do poder, do ser e do saber. Segundo o autor, as culturas indígenas sofreram um processo de colonização eurocêntrica, levando a uma substituição/usurpação das relações comerciais praticadas em contexto tradicional. O interesse do mundo capitalista é buscar um novo mercado rentável, que retira bens comerciais e recursos de terras e saberes indígenas, além de retirar os sonhos de comunidades culturalmente tradicionais e negligenciar o equilíbrio das relações econômicas tradicionais em contexto indígena.

Associado ao patrimônio comercial, biocultural e ao processo colonial, é importante reconhecer o vasto patrimônio sociocultural que possui nosso país. Observa-se a utilização inadequada dos conhecimentos tradicionais indígenas, ainda que o artigo 216, inciso III, da Constituição Federal de 1988 (BRASIL, 1988), estabeleça incentivos e valorizações para as produções e os conhecimentos de bens e valores culturais.

\footnotetext{
14 "Etnodesenvolvimento significa desenvolvimento com identidades culturais" (STAVENHAGEM, 1984, p.
} 68). 
O direito indígena presente na Constituição abarca a natureza coletiva dos povos pelo usufruto exclusivo de seus recursos, suas terras e trocas comerciais. Esses povos possuem direitos sobre os recursos genéticos e materiais presentes em suas terras, ligados ou não ao conhecimento ancestral, além de exercerem sua autonomia analítica acerca das mudanças comerciais e culturais ocorridas em seus territórios por intermédio de influências exteriores às suas realidades.

O grande problema que apontamos é a alienação/usurpação das relações comerciais praticadas em contextos indígenas pela sociedade envolvente. Como os povos indígenas residem em áreas do território brasileiro de grande riqueza genética e fauna, são muitos os interesses econômicos escusos que rondam suas terras. O dilema é o reconhecimento do valor de seu patrimônio e garantir-lhes o direito à escolha e aos possíveis benefícios, visto que a Constituição de 1988 não reconhece o usufruto dos recursos genéticos, mas só o identifica após a validação presente no artigo 231. É fato que os conhecimentos indígenas constituem fonte infindável para o mercado consumidor que, predatoriamente, visa exclusivamente o lucro. Segundo Marés (2010, p. 81),

A população Ocidental, despreza esses conhecimentos quando não há nenhuma expectativa de lucro ou vantagens, o que abre o caminho para o extermínio das populações e de seus saberes; ou facilitam a rapinagem das empresas sobre esses conhecimentos.

Para o autor, onde existem indígenas pode ${ }^{15}$ haver biodiversidade e recursos naturais. A questão de reconhecimento de patrimônio perpassa o habitat, as relações comerciais, as práticas socioculturais e as tradições históricas. É permanentemente agressiva a postura colonialista no que tange à preservação dos direitos indígenas, bem como à proteção de seus conhecimentos tradicionais, o que fomenta processos criminosos de exploração de seus recursos e de suas culturas ao longo da História. A importância da busca de assegurar os conhecimentos tradicionais e os recursos naturais, bem como o patrimônio cultural dos povos indígenas, parte do princípio do reconhecimento, da preservação e da luta.

Temos buscado evidenciar até aqui a difícil situação enfrentada pelos povos indígenas no necessário enfrentamento das práticas capitalistas que objetivam explorar seus espaços sociais, culturais e territoriais. Buscamos ainda associar esse contexto de luta a questões jurídicas e comerciais, enfatizando a importância da valorização e da preservação do

\footnotetext{
${ }^{15}$ Não são todos os lugares. Existem povos que vivem em áreas minúsculas e superpopulosas, de modo que a biodiversidade e recursos naturais já se esgotaram.
} 
conhecimento e das relações comerciais tradicionais como meios de sustentabilidade. Entendemos ser fundamental articular reflexões e argumentos associados ao comércio, à diversidade sociocultural e à biopirataria.

Para que as relações comerciais, os territórios e as culturas indígenas não fiquem à mercê da exploração econômica é importante efetiva regulação protetiva pelo estado brasileiro. Caso contrário, a usurpação econômica permanecerá trazendo prejuízos inestimáveis para sujeitos e saberes indígenas. É importante frisar que o conhecimento indígena há séculos vem sendo utilizado por inúmeras pessoas, países e instituições financeiras. Essa utilização se torna perversa quando alicerçada pela geração indébita de patentes que restringem a utilização de saberes tradicionais pelos seus próprios construtores, o que impede o usufruto na busca pela autossustentabilidade. Trata-se de claro cenário de guerra comercial e apropriação indevida de saberes alheios.

\section{A BIOPIRATARIA E AS "VANTAGENS" ECONÔMICAS EM RELAÇÃO ÀS PRÁTICAS COMERCIAIS INDÍGENAS}

Os desprovidos não são aqueles que ficaram para trás por serem incapazes de aceitar as regras do capitalismo, mas sim aqueles que ficaram excluídos das regras e foram impedidos de ter acesso aos recursos econômicos (SHIVA, 2010). Diante desse princípio, iniciamos a presente seção com uma problematização da prática da biopirataria, as mudanças nas relações comerciais tradicionais indígenas e o impacto dessa exploração para o desenvolvimento social e econômico desses povos.

A economia de mercado percebeu várias vantagens na exploração e venda oriundas da diversidade, dos conhecimentos e dos produtos tradicionais indígenas. Essa modalidade de biopirataria é um tema relativamente novo, ainda não existe regulação efetiva para coibir o uso de produtos/mercadorias sem o pagamento dos royalties ${ }^{16}$ pelo emprego dos conhecimentos tradicionais. Algumas ordens foram criadas, mas não atuam a contento contra essa ação, por exemplo, a Lei $n^{\circ}$ 9605, de 12 de fevereiro de 1998 (BRASIL, 1988), que dispõe acerca dos crimes contra o meio ambiente.

\footnotetext{
${ }^{16}$ Royalties é uma palavra em inglês que significa regalia ou privilégio. Consiste em uma quantia que é paga por alguém ao proprietário pelo direito de usar, explorar ou comercializar um produto, obra, terreno, etc. Essa palavra é o plural de royalty, que significa realeza. Disponível em: https://www.significados.com.br/royalties. Acesso em: 28 de ago. de 2017.
} 
É fato que, no Brasil, a prática da biopirataria vem desde a chegada dos portugueses, em 1500. Com a chegada do cientista Charles M. de La Condemine, na Amazônia, na década de 1740, essa prática se torna mais evidente na região norte do território brasileiro. O início desses processos predatórios é marcado por meio da seringueira contrabandeada para vários países, quando foram desviadas em média 70 mil sementes (SHIVA, 2010). O conceito de biopirataria surgiu em 1992, por meio da Fundação Internacional para o Progresso Rural (ONG RAFI), que o criou como alerta, visto que os conhecimentos e os comércios dos povos indígenas são patenteados por inúmeras multinacionais que sequer disponibilizam lucros e créditos gerados pela utilização desses saberes para a população originária.

Dessa maneira, a biopirataria tem sentido de "apropriação/exploração de conhecimentos tradicionais e de recursos genéticos de algumas comunidades indígenas por indivíduos ou instituição que procuram o controle exclusivo do monopólio" (BARBIERI, 2014, p. 145), referente às relações comerciais dos povos indígenas perante à sociedade envolvente.

Conforme o Instituto Brasileiro de Direito e Comércio Internacional da Tecnologia da Informação e Desenvolvimentos (IBDCITID), a conceituação da biopirataria consiste em "transferência" e "modificação" de recursos genéticos e financeiros e de conhecimentos tradicionais vinculados à biodiversidade e ao comércio sem autorização do Estado e das comunidades locais. Dessa forma, trazemos abaixo o Quadro 1, no qual se apresenta conceitos de biopirataria de diversos autores.

\begin{tabular}{|c|c|}
\hline Autores & Conceito \\
\hline Maria Helena Diniz (2006) & $\begin{array}{c}\text { Patrimônio genético de um país por empresas multinacionais } \\
\text { para atender a fins industriais e lucrativos. }\end{array}$ \\
\hline Celso Fiorillo e Adriana Diaféria (2009) & Perspectiva de dominação sobre a população periférica. \\
\hline Vandana Shiva (2010) & Descoberta. \\
\hline Barbieri (2014) & Apropriação indevida da cultura. \\
\hline
\end{tabular}

Quadro I: Conceituação de biopirataria

Fonte: Adaptado de Barbieri (2014)

Pelas breves conceituações acima, é possível perceber que as visões de Diniz (2006) e Barbieri (2014) se aproximam da conceituação proposta pelo IBDCITID. De tal maneira, temos que essa prática parte de princípios da colonização e da dominação comercial em larga escala frente a povos subalternizados. Consoante às ideias de Shiva (2001), existem mais de 120 princípios ativos em plantas superiores que são utilizados pela Medicina, sendo que $75 \%$ deles foram identificados pelos povos indígenas. O uso dos conhecimentos dessa população torna 
eficaz o reconhecimento das plantas medicinais em mais de 400\% (BARBIERI, 2014). Esses dados nos inquietam e fornecem subsídios para que possamos debater o tema diante das relações de comércio tradicional dos povos originários e da sociedade envolvente, impostas e manipuladas pelo capitalismo.

O Brasil, país marcado pela diversidade, foi e é alvo da biopirataria, fato recorrente devido à riqueza dos conhecimentos oriundos de espaços socioculturais indígenas, os quais são explorados sem a devida regulação, causando sérios prejuízos aos habitantes primeiros do território brasileiro. Podemos elencar alguns produtos alimentícios provenientes de terras indígenas que foram patenteados e explorados dentro e fora do Brasil, ver Quadro II, como: andiroba, ayahuasca, castanha do pará, piquiá, jambu, vacina-de-sapo, entre outros.

\begin{tabular}{|c|c|c|c|c|}
\hline $\begin{array}{c}\text { Produto } \\
\text { (Alimentício) }\end{array}$ & $\begin{array}{c}\text { Origem } \\
\text { (Etnia e/ou região) }\end{array}$ & $\begin{array}{l}\text { Utilização } \\
\text { tradicional }\end{array}$ & Patenteamento & Utilização Ocidental \\
\hline Cupuaçu & Tikuna & $\begin{array}{l}\text { Nascimentos } \\
\text { dificeis e dores } \\
\text { abdominais }\end{array}$ & $\begin{array}{c}\text { Japão, Inglaterra e } \\
\text { Europa }\end{array}$ & $\begin{array}{c}\text { Chocolate, suco, } \\
\text { alimentares e derivados }\end{array}$ \\
\hline Açaí & Amazônia & $\begin{array}{c}\text { Combate à } \\
\text { hemorragia e } \\
\text { verminoses }\end{array}$ & União Europeia & $\begin{array}{c}\text { Vinho, suco, alimentares } \\
\text { e derivados }\end{array}$ \\
\hline Andiroba & Amazônia & $\begin{array}{c}\text { Combate de } \\
\text { insetos e vômitos }\end{array}$ & $\begin{array}{l}\text { França, Japão, } \\
\text { Europa e USA }\end{array}$ & $\begin{array}{c}\text { Tratamento respiratório e } \\
\text { dermatites }\end{array}$ \\
\hline Copaíba & Amazônia & $\begin{array}{c}\text { Anti-inflamatório } \\
\text { e função } \\
\text { terapêutica }\end{array}$ & França e USA & $\begin{array}{c}\text { Função cosmética e } \\
\text { alimentares }\end{array}$ \\
\hline Cipó da alma & Amazônia & $\begin{array}{l}\text { Cerimônia } \\
\text { tradicional }\end{array}$ & Estados Unidos & Destilados \\
\hline Vacina de Sapo & Amazônia & $\begin{array}{l}\text { Regular funções } \\
\text { corporais }\end{array}$ & $\begin{array}{c}\text { USA, Europa e } \\
\text { Japão }\end{array}$ & Antibióticos \\
\hline Jaborandi & Norte do Brasil & $\begin{array}{c}\text { Chás diuréticos e } \\
\text { expectorantes }\end{array}$ & $\begin{array}{c}\text { Inglaterra, USA, } \\
\text { Canadá, Irlanda, } \\
\text { Itália, Bulgária e } \\
\text { Rússia }\end{array}$ & $\begin{array}{l}\text { Tratamento de calvície e } \\
\text { controle do glaucoma }\end{array}$ \\
\hline Jambu & Norte do Brasil & $\begin{array}{c}\text { Tratamento de } \\
\text { anemia, dispepsia } \\
\text { e malária }\end{array}$ & $\begin{array}{c}\text { Japão, Inglaterra e } \\
\text { Estados Unidos }\end{array}$ & Função cosmética \\
\hline $\begin{array}{l}\text { Veneno de } \\
\text { Jararaca }\end{array}$ & Amazônia & $\begin{array}{c}\text { Tratamento de } \\
\text { hipertensão }\end{array}$ & França & Perfume Chanel $n^{\circ} 5$ \\
\hline Pau rosa & Tapajós & $\begin{array}{l}\text { Cerimônia } \\
\text { tradicional }\end{array}$ & França & Perfume Chanel $n^{\circ} 5$ \\
\hline
\end{tabular}

Quadro II - Patenteamento de produto/comercialização Fonte: Adaptado de Barbieri (2014)

Diante do evidente e continuado cenário de exploração, a proteção dos conhecimentos e das relações comerciais dos povos indígenas necessita prever um regime patentário que contribua para o seu próprio etnodesenvolvimento, assegurando-lhes a comercialização de seus produtos e/ou conhecimentos de forma justa, a partir de seus critérios e valores culturais, com 
reconhecimento e concordância a esta sabedoria, sem exploração, usurpação e manipulação de suas relações. Transitaremos o debate acerca da biotecnologia como parte do pressuposto do desenvolvimento econômico e dos mercados consumidores que, por meio da biopirataria, exploram experimentos, saberes e fazeres tradicionais pela influência do capitalismo.

A biotecnologia foi discutida na esfera financeira por Wall Street ${ }^{17}$ como conjunto de meios, técnicas e ferramentas utilizadas para gerar produtos úteis e experimentos científicos. A definição do termo é bem ampla e abrange desde o uso de organismos até atividades humanas. A evolução da biopirataria, nos dizeres de Barbieri (2014), acarreta várias mudanças: além de alterar a vida pessoal e comunitária dos povos indígenas, desrespeita conhecimentos estruturantes de direitos humanos, jogando contra a dinâmica da identidade cultural e imaterial desses povos.

Mediante a propensão do patenteamento, a modificação das relações econômicas é assustadora e não possibilita qualquer benefício aos detentores e aos titulares dos conhecimentos. "Anísio Guató, líder indígena do Pantanal, alertou: há 14 anos os países discutem o uso do conhecimento tradicional. Mas, até hoje nossos conhecimentos permanecem desprotegidos da biopirataria" (CARRASCO; PALÁCIOS, 2012, p. 147).

O universo dos recursos que são deslocados sem qualquer pagamento de royalties aos povos indígenas e sem transparência relativa aos lucros obtidos, faz o mercado capitalista movimentar milhões por ano sem a menor preocupação e contraprestação das vantagens obtidas por meio desta prática nefasta. É necessária regulação governamental para que haja controle efetivo sobre ações dessa natureza. Desta forma, fica evidente o descaso, a posse inadequada da biodiversidade e dos bens tradicionais - propriedade intelectual. Ainda observamos falta de regulação e proteção da biodiversidade e dos conhecimentos tradicionais diante da exploração comercial proveniente da biopirataria.

"Os direitos de propriedade intelectual conferem ao titular o direito de exploração exclusiva de um determinado produto por certo período de tempo, e depois a patente cai em domínio público" (BARBIERI, 2014, p. 167). Por meio do sistema ostensivo, os produtos desenvolvidos nos países com imensa riqueza de biodiversidade, e conhecimento milenares, são voltados ao serviço privado, que é o titular das propriedades intelectuais.

$\underline{17}$ É considerada o coração histórico do atual Distrito Financeiro da cidade de Nova Iorque. 
De acordo com Santilli (2005), os conhecimentos milenares enfocam a importância sustentável para os povos indígenas, sendo necessário um sistema sui generis ${ }^{18}$ sem alteração e manipulação dos pressupostos conceituais - livre de explorações e propriedades intelectuais.

É importante considerar um sistema baseado na especificidade dos direitos dos indígenas no marco do Direito Público. Isso requer análise histórica, sociocultural e antropológica. Conhecimentos ancestrais e milenares demandam o reconhecimento e a preservação cultural e não a exploração das relações comerciais alicerçada em uma lógica capitalista perversa.

Os saberes dos povos indígenas, nos dizeres da Constituição, segundo o artigo 225 (BRASIL, 1988), não são públicos nem privados; são comuns a esses povos originários. Esperase que esse entendimento seja protegido e conservado, embasando a luta anticolonialista contra relações comerciais ilegais que colocam em risco a biodiversidade e a história desses povos.

\section{A BIOPIRATARIA NA AMAZÔNIA COMO AÇÃO NEFASTA PARA AS RELAÇÕES COMERCIAIS}

Em contexto de biopirataria, a comercialização ilegal é caracterizada pela utilização de conhecimentos tradicionais por intermédio de mercados consumidores capitalistas. É comum observar multinacionais e/ou empresários não se darem à tarefa de solicitar formalmente autorização legal ao governo (IBAMA, FUNAI, entre outros) para o desenvolvimento de suas pesquisas. "O projeto de lei que regula o acesso aos recursos genéticos e aos conhecimentos tradicionais continua parado [...] enquanto isso, a biopirataria avança a números alarmantes" (HOMMA, 2010, p. 2).

Parte importante dos entorpecentes utilizados pela Medicina ocidental é derivada de plantas tradicionais cujo uso medicinal foi desenvolvido por povos indígenas. Esses produtos originaram um mercado expansivo e dinamizador que recebeu vantagens econômicas provenientes de apropriações dos saberes indígenas, na maioria das vezes, sem consentimento.

Para o Instituto Nacional de Pesquisas da Amazônia (INPA), a utilização desses saberes não fere o direito e a forma de viver desses povos. Contudo, quando há patenteamento e exploração dos recursos comerciais e imateriais sem distribuição dos lucros e reconhecimento de autoria, ocorre violação de direitos.

\footnotetext{
${ }^{18}$ De acordo com o Dicionário Aurélio, sui generis refere-se a algo sem semelhança com nenhum outro, único em seu gênero, original, peculiar, singular. 
A prática da biopirataria na Amazônia é o tripé do mercado econômico - consumidor que movimenta U\$100 milhões por ano nas indústrias farmacêuticas. $\mathrm{O}$ Brasi1 ${ }^{19}$ não possui um único centavo desse recurso (NASCIMENTO, 2010). Presentemente, o uso expansivo dos saberes indígenas por intermédio da biopirataria é nefasto e representa um grande prejuízo para a sociedade nacional.

Esses dados são alarmantes. Existe uma ausência por parte do Estado nos debates jurídicos que determinam a preservação e a conservação da biodiversidade associada à cultura e ao comércio indígena. Imediatamente questionamos: onde estão os créditos/rendimentos de direito dos povos indígenas? É necessário dividir as vantagens obtidas por meio desta prática econômica? Para Barbieri (2014), a resposta se torna ainda mais complexa quando muito do conhecimento indígena já é considerado de domínio público.

O problema da divisão justa de vantagens é complexo. A autora relata uma ação em terras Baniwa, onde houve distribuição justa de benefícios não econômicos, em comum acordo, para a etnia da comunidade do Alto Rio Negro. Corroborando os apontamentos acima, Baniwa (apud, BARBIERI, 2014, p. 174-175) nos diz:

\begin{abstract}
Nós passamos a contribuir com eles, mercado, fornecendo várias informações que tínhamos e eles atenderam nossas demandas, como realizar um encontro de educação e trazer informações sobre nossos direitos. A gente foi se aperfeiçoando em oficinas linguísticas, na unificação da grafia baniwa, na elaboração de um projeto-escola baniwa voltado para as formações de professores que não tínhamos. Atualmente, temos mais de 200 professores e uma escola de quinta a oitava série [...]. Para nós não veio benefício em dinheiro, mas talvez, esse que veio, tenha sido bem melhor do que se viesse em dinheiro [...]. Hoje nós temos autoestima, somos mais respeitados, participamos de algumas decisões do Conselho de Gestão do Patrimônio Genético (CGEN). Além da questão financeira isso traz o fortalecimento da nossa organização indígena, tanto para o índio quanto para os pesquisadores existem benefícios nessa história de contribuir $[\ldots]$.
\end{abstract}

Este exemplo é relevante: a divisão, de acordo com a opinião de lideranças da etnia Baniwa, é fruto de uma associação mútua; deu-se sem a compensação econômica, mas possibilitou grandes benefícios à comunidade, resultados de negociações saudáveis, sem "presença" de usurpação ou manipulação comercial. Não obstante, concebemos o grande prejuízo para os povos indígenas quando ocorre apropriação e comercialização indevida de seus produtos e saberes. Em vista disso, é fácil observar a resistência e a ação dos povos indígenas em salvaguardar seu patrimônio imaterial e cultural associado à biodiversidade e às relações comerciais envolventes (COLL, 1974).

19 Tampouco os povos indígenas que são "usurpados" frente aos conhecimentos que foram explorados e possibilitaram a fabricação de produtos industrializados e vendidos à sociedade envolvente. 
São flagrantes as injustiças cometidas com o patenteamento e a comercialização indevida de conhecimentos tradicionais indígenas. Trata-se de exploração predatória que vem sendo cometida por diversas empresas ao longo do tempo. Em 2006, segundo a Agência de Notícias da Amazônia (ANA), o IBAMA fez um estudo que estimou, mediante pesquisas realizadas desde 2003, que as perdas econômicas diárias chegam a U\$16 milhões, devido à prática da biopirataria, que saqueia o conhecimento e o comércio indígena, exportando-os para outros países, em forma de relações comerciais lucrativas. A falta de políticas de reconhecimento e de devida valorização das comunidades tradicionais fundamenta-se na pretensa escassez de recursos financeiros - uma vez que tais políticas acabam sendo preteridas em detrimento de tantas outras. O mesmo estado, contudo, é permissivo com essas práticas, das quais resultam perdas de diferentes naturezas (SILVA, 2018).

Há diversos pesquisadores e instituições que lutam contra essa prática ilegal, por meio de pesquisas e colaborações. Os intuitos destas ações, além de proteger o patrimônio sociocultural das comunidades indígenas, são de minimizar o caráter financeiro exploratório das relações que retêm bilhões de reais por meio de usurpação de conhecimentos ancestrais.

As considerações propostas pelo Ibama são elucidativas e revelam o quanto é crucial lutar para eliminar essa prática. O estudo supracitado chegou à conclusão de que essa ação é uma tentativa de (re)colonização de nações em desenvolvimento promovida por nações ricas, ditas desenvolvidas. Segundo a Secretaria do Meio Ambiente do Governo do Estado da Bahia (MAGEB), em análise realizada em 2009, os prejuízos econômicos para os povos indígenas brasileiros chegam a $\mathrm{R} \$ 240$ milhões por ano.

Diante do continuado interesse de estrangeiros em realizar pesquisas com fins comerciais, a ação da biopirataria permanece crescendo. Para o Departamento de Patrimônio Genético do Ministério do Meio Ambiente (DPGMMA), os prejuízos são arrasadores para os detentores dos conhecimentos tradicionais. Ainda assim, o Estado não tem se afligido nem com a usurpação de saberes ancestrais nem com a exploração de recursos naturais. Perante essa circunstância, é fundamental uma ação nacional, com fundamentação legal, que represe a prática, porquanto o que vivenciamos é uma recolonização tanto em contexto sociocultural quanto no comercial e formativo (SILVA, 2018).

Em 2006, ao final do relatório da Comissão Parlamentar de Inquérito destinada à investigação do tráfico de animais e plantas silvestres brasileiros, da exploração e do comércio ilegal de madeira e da biopirataria no País (CPIBIOPI), Sarney Filho sugeriu novas políticas públicas para eliminar a prática exploratória da biopirataria em terras indígenas, porém, 
segundo o deputado, faltava espaço para debater a questão. Contudo, é colocada em pauta a falta de incentivo a pesquisadores que focam sua atividade acadêmica na diversidade; a falta de apoio ao combate à prática da biopirataria e às relações comerciais ilegais (Barbieri, 2014); não existe, ainda, fiscalização efetiva sobre tais atividades nem sequer sobre o patenteamento genético; e as políticas nacionais são incipientes.

Em cenário de descontrole sobre a biopirataria, afeta-se a soberania nacional. Até hoje não existe definição única sobre biopirataria na legislação brasileira. É essencial que as leis sejam revigoradas e harmonizadas, respeitando os saberes locais. Assim, esperamos novas políticas públicas que busquem a promoção sustentável, adequando-se às exigências ambientais e aos conhecimentos - comerciais e não comerciais - dos povos indígenas.

\section{A FALTA DE REGULAÇÃo ECONÔMICA NO CENÁRIO INDÍGENA: CAMINHOS QUE SURGIRAM ATÉ AQUI}

As problematizações e os relatos-denúncias que investigamos, voltados ao processo de subalternação e (re)colonização comercial em cenários indígenas na Amazônia, vieram ao encontro de nossas inquietações acerca das consequências da prática da biopirataria sobre culturas e práticas econômicas dos povos indígenas brasileiros. A riqueza da diversidade sociocultural brasileira gera modos próprios de enxergar o meio e o mundo capitalista.

Buscamos refletir sobre o processo de subalternação e (re)colonização comercial, revelando relações exploratórias que cotidianamente violentam povos indígenas na realidade brasileira, especialmente na Amazônia. O texto se voltou para construção de argumentação reflexiva sobre as influências de determinada lógica do capital que invade territórios colonizados, modificando dinâmicas socioculturais próprias. Tendo como aporte a consciência de que valorizar as culturas indígenas brasileiras significa problematizar as ações invasivas que as acometem, pudemos desvelar impactos/influências que ferem modos de vida indígenas, desequilibrando-os por meio de ações comerciais predatórias.

As reflexões realizadas são decorrentes da matriz de poder proposta por Quijano (2000). Submeter militarmente os povos indígenas e dominá-los com o uso de força ou de exploração comercial de seus saberes tem sido prática comum na história do Brasil. Esse artigo busca evidenciar a necessidade de rompimento radical com formas colonialistas de conceber o mundo, de enxergar as relações interculturais e de lidar com a realidade circundante. Adotar como próprio horizonte cognitivo o campo do dominador é prática colonial perversa que permanece latente no território brasileiro. 
A prática colonialista da dominação agride as práticas comerciais tradicionais indígenas, as fronteiras culturais, a biodiversidade, a biotecnologia e os conhecimentos em geral dos povos originários, sendo ocasionada por segmentos da sociedade nacional que detêm poder econômico e movimentam-se de modo articulado com as explorações ocorridas na Amazônia e em outros cenários brasileiros.

Dessa forma, foi fundamental mencionarmos o direito dos indígenas aos seus conhecimentos ancestrais como ação da pessoa humana, subsistindo com sua cosmovisão. É explícito que seu legado cultural imaterial decorre de conhecimentos milenares. Seu conhecimento contextualmente produzido ${ }^{20}$ é explorado, manipulado e mercantilizado ilegalmente por empresas multinacionais que colocam, no sistema comercial mundial, produtos de saberes indígenas. Essa atividade é um crime; só perdendo monetariamente para o tráfico de drogas.

Ao nosso ver, é importante compreender o que está secularmente invisibilizado, busca para a qual não se tem interpretação única. Acreditamos que o debate sobre a prática ilegal da biopirataria na Amazônia não produz e tampouco socializa novas formas de comercializar. De tal modo, esperamos é que se cumpram as leis prescritas pela Constituição Federal de 1988 e se reconheçam os distintos povos indígenas, bem como a promoção de autonomias para que os mesmos possam enfrentar as várias transformações econômicas e políticas em diversas situações vividas.

A partir das leis estabelecidas é importante gerar regulação efetiva para combater processos exploratórios de saberes indígenas, pois os desfalques nas culturas compõem a trajetória do capitalismo, conduzindo multidões para um cenário de dependência econômica: houve tentativas de regulação do acesso aos recursos econômicos e genéticos, contudo, de forma lenta e ineficaz. É prática histórica comum em nosso país limitar o registro do patrimônio cultural e imaterial que relaciona o conhecimento tradicional ao genético. Logo, são necessárias jurisprudências efetivas que reprimam a prática da biopirataria para que as comunidades indígenas possam, conforme seu desejo, permitir ou não o acesso a seu conhecimento associado à biodiversidade, sem serem forçosamente submetidas à exploração de sua cultura e de suas práticas comerciais.

Esperamos que os argumentos expressos aqui constituam instrumento útil ao protagonismo dos povos indígenas - enquanto pauta combativa de luta e de resistência - no

${ }^{20}$ Produção de artesanatos, trocas entre famílias, fabricação de utensílios, ferramentas domésticas, entre outros. 
desenvolvimento e na tomada de decisão acerca das relações comerciais promovidas em suas comunidades. Esperamos ainda que o estudo seja relevante como conteúdo a ser trabalhado em processos formativos - de distintas áreas de conhecimento e, em especial, em contexto de ensino de ciências e matemática - voltados tanto aos povos indígenas quanto aos não indígenas.

\section{REFERÊNCIAS}

BARBIERI, S. R. J. Biopirataria e povos indígenas. 1. ed. São Paulo: Almedina, 2014.

BOND, R. História do caminho de Peabiru. 1. ed. Rio de Janeiro: Ediouro, 2010.

BRASIL. Constituição Federal de 1988. Brasília: MEC, 1988.

BRASIL. Leis de crimes ambientais: lei 9605/98 de 12 de fevereiro de 1988. Brasília: MEC, 1988. Disponível em: https://tecnoblog.net/360529/como-citar-leis-nas-normas-abnt/. Acesso em: 23 abr. 2021.

CARRASCO, L.; PALACIOS, S. Quem manipula os povos indígenas: contra o desenvolvimento do Brasil. 2. ed. Rio de Janeiro: Capaxdei, 2013.

CASTILHO, E. W. V. Direitos humanos das populações indígenas. In: CASTILHO, E. W. V. (org.). Direitos Humanos, Brasília, n. 3, p. 19-22, 2009.

COLL, J. O. A resistência indígena: do México à Patagônia, a história da luta dos índios contra os conquistadores. 2. ed. Porto Alegre, RS: L\&PM Editores, 1974.

HOMMA, A. K. O. Biopirataria na Amazônia, como reduzir os riscos? Amazônia: Ci. \& Desenv., Belém, PA, v. 1, n. 1, p. 47-60, jul./dez. 2005. Disponível em:

https://ainfo.cnptia.embrapa.br/digital/bitstream/item/30451/1/BiopiratariaAmazonia.pdf.

Acesso em: 23 abr. 2021.

LARAIA, R. B. Cultura: um conceito antropológico. 15. ed. Rio de Janeiro: Jorge Zahar Ed., 2002.

MARÉS, F. O renascer dos povos indígenas para o direito. 2. ed. Curitiba: Juruá Editora, 2010.

NASCIMENTO, D. L. Biopirataria na Amazônia. 1. ed. Curitiba: Juruá, 2010.

ORGANIZAÇÃO DAS NAÇÕES UNIDAS. Declaração Universal dos Direitos Humanos, 1948. Disponível em: https://www.unicef.org/brazil/declaracao-universal-dos-direitos-

humanos. Acesso em: 23 abr. 2021.

ORGANIZAÇÃO DAS NAÇÕES UNIDAS. Declaração Universal dos Povos Indígenas, 2008. Disponível em:

https://www.acnur.org/fileadmin/Documentos/portugues/BDL/Declaracao das Nacoes Unid as sobre os Direitos dos Povos Indigenas.pdf. Acesso em: 23 abr. 2021. 
QUIJANO, A. Colonialidade do poder, eurocentrismo e américa latina. 1. Ed. Buenos Aires: Consejo Latinoamericano de Ciencias Sociales, 2000.

SANTILLI, J. Multiculturalismo e direitos coletivos: socioambientalismo e novos direitos. 1. ed. São Paulo: Petrópolis, 2005.

SHIVA. Biopirataria: a pilhagem da natureza e do conhecimento. 1.ed. Petrópolis: Vozes, 2001.

SILVA, M. M. Etnomatemática e relações comerciais na formação de professores indígenas. 2018. Dissertação (Mestrado em Educação em Ciências e Matemática) - Programa de Pós-Graduação em Educação em Ciências e Matemática, Universidade Federal de Goiás, 2018. Disponível em:

https://repositorio.bc.ufg.br/tede/bitstream/tede/8242/5/Disserta $\% \mathrm{C3} \% \mathrm{~A} 7 \% \mathrm{C} 3 \% \mathrm{~A} 30 \% 20$ \%20Matheus\%20Moreira\%20da\%20Silva\%20-\%202018.pdf. Acesso em: 23 abr. 2021.

STAVENHAGEM, R. Etnodesenvolvimento: uma dimensão ignorada no pensamento desenvolvimentista. Brasília: UNB, 1984.

TAUKANE, E. B. Minha formação, meu povo: um só objetivo. In: Taukane, E. B. Caderno de educação escolar indígena. Barra do Bugres, MT: UNEMAT, v. 2, n. 1, p. 11-18, 2003.

\section{NOTAS}

\section{AGRADECIMENTOS}

Não se aplica.

FINANCIAMENTO

Não se aplica.

\section{CONTRIBUIÇÕES DE AUTORIA}

Resumo/Abstract/Resumen: Matheus Moreira da Silva, José Pedro Machado Ribeiro e Rogério Ferreira. Introdução: Matheus Moreira da Silva, José Pedro Machado Ribeiro e Rogério Ferreira.

Referencial teórico: Matheus Moreira da Silva, José Pedro Machado Ribeiro e Rogério Ferreira.

Análise de dados: Matheus Moreira da Silva, José Pedro Machado Ribeiro e Rogério Ferreira.

Discussão dos resultados: Matheus Moreira da Silva, José Pedro Machado Ribeiro e Rogério Ferreira.

Conclusão e considerações finais: Matheus Moreira da Silva, José Pedro Machado Ribeiro e Rogério Ferreira.

Referências: Matheus Moreira da Silva, José Pedro Machado Ribeiro e Rogério Ferreira.

Revisão do manuscrito: José Pedro Machado Ribeiro e Rogério Ferreira.

\section{CONFLITOS DE INTERESSE}

Declaramos não haver nenhum conflito de interesse de ordem pessoal, comercial, acadêmico, político e financeiro referente a este manuscrito.

DISPONIBILIDADE DE DADOS DE PESQUISA

O conjunto de dados que dá suporte aos resultados da pesquisa foi publicado no próprio artigo.

CONSENTIMENTO DE USO DE IMAGEM

"Não se aplica." 
APROVAÇÃO DE COMITÊ DE ÉTICA EM PESQUISA

"Não se aplica."

\section{COMO CITAR - ABNT}

SILVA, Matheus Moreira da; RIBEIRO, José Pedro Machado; FERREIRA, Rogério. Biopirataria e explorações ocorridas no Brasil: um relato-denúncia de práticas criminosas contra povos indígenas. REAMEC - Rede Amazônica de Educação em Ciências e Matemática. Cuiabá, v. 9, n. 1, e21031, janeiro-abril, 2021. https://doi.org/10.26571/reamec.v9i1.11668

\section{COMO CITAR - APA}

Silva, M. M. da; Ribeiro, J. P. M.; Ferreira, R. (2021). Biopirataria e explorações ocorridas no Brasil: um relatodenúncia de práticas criminosas contra povos indígenas. REAMEC - Rede Amazônica de Educação em Ciências e Matemática, 9(1), e21031. https://doi.org/10.26571/reamec.v9i1.11668

\section{LICENÇA DE USO}

Licenciado sob a Licença Creative Commons Attribution-NonCommercial 4.0 International (CC BY-NC 4.0). Esta licença permite compartilhar, copiar, redistribuir o manuscrito em qualquer meio ou formato. Além disso, permite adaptar, remixar, transformar e construir sobre o material, desde que seja atribuído o devido crédito de autoria e publicação inicial neste periódico.

\section{DIREITOS AUTORAIS}

Os direitos autorais são mantidos pelos autores, os quais concedem à Revista REAMEC - Rede Amazônica de Educação em Ciências e Matemática - os direitos exclusivos de primeira publicação. Os autores não serão remunerados pela publicação de trabalhos neste periódico. Os autores têm autorização para assumir contratos adicionais, separadamente, para distribuição não exclusiva da versão do trabalho publicada neste periódico (ex.: publicar em repositório institucional, em site pessoal, publicar uma tradução, ou como capítulo de livro), com reconhecimento de autoria e publicação inicial neste periódico. Os editores da Revista têm o direito de proceder a ajustes textuais e de adequação às normas da publicação.

\section{PUBLISHER}

Universidade Federal de Mato Grosso. Programa de Pós-graduação em Educação em Ciências e Matemática (PPGECEM) da Rede Amazônica de Educação em Ciências e Matemática (REAMEC). Publicação no Portal de Periódicos UFMT. As ideias expressadas neste artigo são de responsabilidade de seus autores, não representando, necessariamente, a opinião dos editores ou da referida universidade.

\section{EDITOR}

\section{Dailson Evangelista Costa (1) 0}

\section{HISTÓRICO}

Submetido: 06 de janeiro de 2021.

Aprovado: 25 de março de 2021.

Publicado: 24 de abril de 2021. 